\title{
Utilization of Modern Contraceptives for Family Planning in Urban Setting: Kitunda Ward of Ilala Municipal, Dar-es-Salaam City, Tanzania
}

\author{
Irene Kessy' ${ }^{1}$ Edmund J. Kayombo ${ }^{*}$ \\ ${ }^{1}$ Muhimbili University of Health and Allied Sciences, Dar-es-Salaam, Tanzania \\ ${ }^{2}$ Institute of Traditional Medicine, Department of Medical Botany, Plant Breeding and Agronomy, Muhimbili \\ University of Health and Allied Sciences, Dar-es-Salaam, Tanzania \\ Email: *edmundkayombo@yahoo.com, *ekayombo@live.com
}

Received 3 November 2015; accepted 18 November 2015; published 24 November 2015

Copyright (C) 2015 by authors and OALib.

This work is licensed under the Creative Commons Attribution International License (CC BY). http://creativecommons.org/licenses/by/4.0/

(c) (i) Open Access

\section{Abstract}

Background: Tanzania is one of countries with low rate $(34 \%)$ on utilization of contraceptives when compared with developed and other developing countries. Objective: The objective of this study was to assess the current use of contraceptives among women of reproductive age (15 - 49 years) in urban areas as case study, and evaluate barriers on utilization of contraceptives at Kitunda ward, Ilala Municipal, Dar-es-Salaam city. Study Design: The study was a cross-sectional study. Three hundred women of reproductive age (15 - 49 years) were interviewed using structured questionnaires for data collection. Two research assistants assisted researchers to interview the sampled child bearing age women. Data Analysis: The collected data were entered in a computer and were analyzed using EPI Info software version 6.0. Results: A total of 300 women were interviewed; $71.9 \%$ were of age ranged 18 - 35 years; and $50.5 \%$ had secondary and college education. The prevalence of contraceptive use was $70 \%$, and injectables ranked first $(30.8 \%)$ followed by pills (27.7\%). Other contraceptive methods used were calendar, rhythm and condoms. Socio-demographic characteristics of women were found to associate with contraceptive use. The most common barriers on utilization of the contraceptives reported include disruption in menstrual cycle, headache, cancer and cardiovascular diseases. It is recommended that there should be an agent need of increasing knowledge by seminar on utilization of all types of contraceptives that spells the usefulness and possible side effects like to occur to users of contraceptives and where to seek health services when such problems occur. This will help users of contraceptive users to have an informed choice which is contraceptive to use for family planning. Above all traditional herbs used for FP should be scientifically studied on their safety and efficacy. They may provide an alternative to present contraceptives that have shown to have side effects.

${ }^{*}$ Corresponding author.

How to cite this paper: Kessy, I. and Kayombo, E.J. (2015) Utilization of Modern Contraceptives for Family Planning in Urban Setting: Kitunda Ward of Ilala Municipal, Dar-es-Salaam City, Tanzania. Open Access Library Journal, 2: e2025.

http://dx.doi.org/10.4236/oalib.1102025 


\title{
Keywords
}

Tanzania, Contraceptives, Family Planning, Child Spacing

\author{
Subject Area: Public Health
}

\section{Introduction}

Tanzania is one of the countries with low rate (34\%) on utilization of contraceptives for family planning [1] when compared with developed and other developing countries [2]-[4]. Of the $34 \%$, seven percent (7\%) are using natural and traditional methods including abstaining. Low use of contraceptives is also reported in Middle Eastern Countries, Asia, Latin America, and the Caribbean and highly felt in sub Saharan Africa and India [3]-[5]. Contraception refers to intentional prevention of conception or impregnation through the use of various devices, agents, drugs, sexual practices, or surgical procedures [6]. Family Planning (FP), on the other hand, means regulating fertility so that couples or individuals get children at a time they want to have a baby and spacing between births [7]. It involves the use of contraception that inhibits possibility of conception.

Literature reviewed shows recorded utilization of contraception which started in the 18th century [8]. Even though contraception was not documented before the 18th century, it was very likely to have started long time ago using natural/traditions contraceptives including abstinence [8]-[11] till to the development of the current conventional contraceptive methods as a result of advancement in technology [10] [11]. People were aware of the importance of the child spacing for the survival of the child. In Africa, for example, there were some beliefs related to raring a child; couples with infants breastfeeding had to adhere to till the child was three years old [9]-[12]. These beliefs included prolonged breastfeeding and postpartum sexual taboos on sexual relation for a health child to grow and survive. Reproductive health was one the important topic taught during the initiation to adulthood [12] [13] to both boys and girls; but more emphases were given to girls [12] [13]. There was a belief (which still exists in some ethnic groups today) if the couple with breastfeeding child had sex within or outside wedlock, that the breastfeeding child suffered from special illness believed to be associated with breaching cultural norms [12] [14]. The couple was scolded by the elders. It was a shame for a woman to get pregnant while the child was still very young or the child suffered from the special illness as a result of breaching the norms. Similar beliefs are reported in other developing countries in the world as well [13] [15] [16]. Herbal remedies is one of the means of managing health problems including family planning where conventional health facilities were not available in Africa. In case remedies for FP was not known a try and error method were used to search herbal remedy that can be used in FP [10] [17]. In some communities these remedies are still used even today in many parts of Africa and other parts of the world [18] [19]. However, no serious study has been done to evaluate the effectiveness of these remedies in contraception. Those who have attempted to study contraceptive herbs have down watered them by arguing that they are not effective as modern contraceptive [18].

All in all, FP gives an opportunity of spacing child and limiting their family size [19] [20]. In addition it gives opportunity to have health baby and reduced maternal morbidity and mortality [7] [11]. Above all, effective use of reliable contraceptives will help to reduce the fast world's population growth — a big cry for demographers [21]. The current world's total population is 7,211,239,210 but the natural resources where these people live are fixed [21]. This vast growth has significant effects on health and economic wellbeing in developing countries [22] [23]. Based on the usefulness of contraceptives on health and economic wellbeing, what are the underlying reasons of low use of contraceptives? Are the underlying reasons applied even in urban areas where health facilities are available for providing health care?

The Family Planning Association of Tanzania (UMATI) introduced modern contraceptive through the FP services in Tanzania in 1959 [24]. In the early years this services were mostly provided in few urban areas with little support from the government. In the 1970s this services were extended to cover more areas in the country. The government became more involved in providing family planning services with the message of child spacing following the launching of the integrated Maternal and Child Health program in 1974, and family planning services was part of maternal and child health services [24]. Child spacing programme did not evaluate the traditional methods that have been used spacing the children.

The importance of family planning in Tanzania is also reflected in the National health policy, National FP 
Costed Implementation Plan that there is need to increase One plan operational target for FP by 2015-increasing modern contraceptive to $60 \%$ [25]. However FP is not spelled out clearly in vision 2025. Further, there is inconstancy budget over the years for FP. The national FP budget increased slightly between the year of 2010/11 to 2011/12 [25]. Since then the national budget allocation for FP has been on the downward trend [25]. The impact of this is inadequacy of the required facilities and contraceptives to the individual prevalence. Hence the possible option is the use of traditional and natural methods for preventing unwanted pregnancy.

According to Tanzania Demographic health survey (TDHS) [1] currently two major types of contraceptives are being used in Tanzania - traditional and natural methods; and modern contraceptives. Traditional methods included herbal remedies believed to prevent conception, lactation, traditional rituals that accompanied with abstaining from sex. Natural contraceptive methods on the other include; withdrawal (coitus interrupts), calendar rhythm, basal body temperature and cervical mucus methods [1]. Despite their usefulness traditional methods of spacing the children before the introduction of modern contraceptives, rare traditional methods were/are promoted as one of important method for contraception [1] for those who cannot use modern contraceptive. Modern contraceptives which are on use on the other hand include; oral pills, inject able hormones, condoms, intrauterine contraceptive devices (IUCD), sub dermal implants and sterilization (tubal ligation and vasectomy) [1]. The methods are being promoted by fliers, mass media and reproductive health services in health facilities worldwide but rarely mention the side effects of contraceptives. Researchers who are in favour of FP argue that modern contraceptive methods prove to be more advantageous than natural ones; more reliable and accurate, some of them for example condoms give protection against STDs (sexually transmitted diseases) including HIV/AIDS [18] [26]. Majority of people who prefer modern methods get an opportunity for screening other health problems. However among the literature reviewed there is no systematic study that has attempted to assess if there is any statistical difference in terms effectiveness in prevent pregnancy among women who have used these two methods at given period of time. Since most studies focus on modern contraceptives users of non modern contraceptives either lie to be using modern contraceptives or refrain by claiming that they do not use contraceptive; but eventually are using traditional and natural methods. These are the areas that have to be investigated.

Despite the enormous resources used in promotion of utilization of modern contraceptives, yet there low utilization of modern methods. Some of obstacles that lead to low use of contraceptives include; lack of knowledge about modern contraception that include uses, benefits and side effects of each; moral or religious values, limited supply and high cost of some preferred method of contraceptive that goes up \$ 100.00 [27]. Also there are health concerns for those who ever used modern contraceptive worldwide [19] [20] [27]. In Tanzania, for example, there has been continuous complains in mass media that modern contraceptives have serious side effects; and these factors lead to discontinuation among women who are using contraceptives. In addition, there are also cultural/personal objections. Cultural and family barriers to family planning influence a woman's decision to use contraception. A husband may disapprove because he wants more children or is concerned about health effects, bothered by the inconvenience, or distrustful of traditional methods [20] [28]. These factors in total partly explain the noted high rates of discontinuation and low use of contraceptive in some developing countries. Are these obstacles found in urban areas where users of contraceptives have access of knowledge, competent family health providers, availability of various contraceptives? What is the rate of use traditional/natural methods of contraceptives in urban settings?

\section{Conceptual Framework}

Low utilization of modern contraceptives in developing countries can be analyzed by assessing availability and accessibility of methods preferred by clients; cultural acceptance and knowledge of modern of contraceptives both advantages and disadvantage for users [10] [20]. A client will choose any contraceptive method if s/he has adequate knowledge, user friendly, cultural accepted with minimum side effects when compared to the one $\mathrm{s} / \mathrm{he}$ uses in terms cost and benefit. A user of any contraceptive methods would way/balancing costs against benefits to arrive at action that maximizes personal advantage on using the contraceptive chosen. In addition, a choice of any contraceptives method can be influenced by patterns of behavior in society where he lives. Thus an individual's choice of any method of contraceptive should not be seen as an egotistical good, but rather a utilitarianistic one under certain circumstances in seeking the most cost-effective means to achieve a specific goal without reflecting on worthiness of that goal. In general, user of contraceptive will prefer to choose the method that provides the greatest reward in terms of effectiveness with minimum side effect at the lowest cost 
Number of studies on contraceptives has been carried in Tanzania and other countries in the world [20] [24]. Focus has been on knowledge attitude and practice on modern contraceptives and utilization. Few studies in Tanzania have attempted to assess utilization of contraceptives in urban setting and hence difficult to establish the claimed side effects if they do exist where health services are available in an urban settings. This paper using the findings of Kitunda ward, Ilala District, Dar-es-Salaam City, Tanzania study aimed to assess the utilization of contraceptives in an urban setting and establish their barriers which were experiences in urban settings. This paper attempts to answer the following questions:

1) What is the status of utilization of contraceptive in urban setting?

2) What type of contraceptives methods commonly being used today and their availability at ward?

3) What are the common health problems do users faces when using these contraceptives and act as barriers?

The answers to these questions would give us a picture on the current use of contraceptive methods in an urban settings and problems encountered.

\section{Rationale}

Contraceptives, used in Family planning (FP) in Tanzania, are one of the components of safe motherhood initiative (SMI), that aims to improve maternal and child health and as well as reducing population growth. This in turn leads to meet $4^{\text {th }}$ and $5^{\text {th }}$ Millennium Development goals (MDGs) and part of Tanzania health Vision 2025 and National health policy to have health wellbeing population in the country. The study was expected to provide relevant information on utilization of contraceptives, barriers on utilization of contraceptives in urban setting and possible effective intervention that would lead to increase users of contraceptives.

\subsection{Research Methodology}

\subsubsection{Study Area}

The study was conducted at Kitunda ward, Ilala Municipal in Dar-es-Salaam City in 2009. The Ilala Municipal is bordered by Kinondoni Municipal, Indian Ocean, Temeke Municipal and the Coastal region. The Municipal has urban, mixed and rural type settlements. According to the [29] National population census, the Ilala Municipal was 1,220,611 and of that $51.2 \%$ were female. The population has doubled from that of 2002 which was 637,573. The Wazaramo was the indigenous in Ilala Municipal, but now it is a mixture of ethnic groups in the municipal because of rural urban migration. Ilala Municipal has a total of 22 wards and 16 of these are urban type and Kitunda ward is one of urban wards. There are two hospitals owned by the government and these are Amana hospital and Muhimbili hospital which is the National referral hospital. There are also several dispensaries district distributed among Wards owned by the government. Besides the government health facilities there are also private hospitals in this Municipal.

\subsubsection{Study Design}

Descriptive cross sectional study was designed for assessing current use of contraceptives for family planning at Kitunda ward, Ilala Municipal, Dar-es-Salaam.

\subsubsection{Study Population}

Study population consisted of women of reproductive age (15 - 49 years) at Kitunda ward, Ilala Municipality. Criteria for involvement in the study included: 1) a women of reproductive age; 2) a resident of that Kitunda ward, Ilala Municipality; 3) present at the time of the study; and 4) should not be severely sick and consent to participate in the study. Exclusion criteria on the other hand, women below and above the stated age, not resident of Kitunda ward and were severely sick.

\subsubsection{Sample Size}

Sample size of this study was calculated by using the following formula proposed by Yamane [30] for estimating the sample size.

$$
N=Z^{2} P(1-P) / E^{2}
$$

where, $N=$ Minimum sample size required;

$$
Z=\text { Normal standard deviation, at } 95 \% \text { confidence interval }=1.96 \text {; }
$$


$P=$ Prevalence rate, $16 \%[1]$

$E=$ Standard maximum error;

$N=1.96^{2} \times 0.26(1-0.26) / 0.05^{2}=295.6$.

Thus minimum sample size was 295.6.

\subsection{Sampling Technique}

Kitunda ward was randomly selected from 22 wards of the municipal. A list of all the streets and number of houses at Kitunda ward was obtained from ward executive office. Using the street and number of household the sample size was selected by systematic sampling from each street and households. Every $6^{\text {th }}$ household from each street was chosen for this study until the intended number was obtained.

\subsection{Data Collection}

A questionnaire was developed and was translated to Kiswahili language for better understanding of the study population. This questionnaire was piloted to Tabata ward, Ilala Municipal a way of testing consistent reliability and face/content validity on assessing current utilization of contraceptive among the reproductive age women. The results of the pilot study were discussed by researchers, and amendment of the questionnaire was done where it was not clear. The refined tool of data collection was administered by the research assistant to the sampled target population. Serial numbers was used instead of names. The research assistants were closely supervised by the researchers while filling-in the questionnaires. The filled in questionnaires were rechecked if were properly filled before leaving the study area.

\subsection{Data Management and Analysis}

Data from individual questionnaire were coded, entered in the computer and were cleaned for checking any possible errors before analyzing. The cleaned data were analyzed using EPI Info software version 3.5.1 for calculating frequency, percentage and $X$ test of the study sample on utilization of contraceptives. The analyzed data were reviewed several times; and then were summarized and results are presented below.

\subsection{Ethical Considerations}

Permission was obtained from the School of Public Health (MUHAS). The letter was provided and was taken to the Ilala Municipal local government. The Local government Municipality wrote a letter of introducing researchers to Kitunda Ward executive officer where the study was carried. Individual consent was oral sought and confidentiality was guaranteed for the participants. Code numbers were used in the questionnaire instead of names.

\section{Results}

\subsection{Socio-Demographic Characteristics of Participants}

A total of 300 respondents of reproductive age were involved in the study $216(72 \%)$ were in age group (18 - 35) years, $71(23.7 \%)$ were from age group $(>35)$ years and $13(4.3 \%)$ were from age group $(<18)$ years (see Table 1). Most of the correspondents had secondary and college education $152(50.7 \%)$ followed by those who had primary education $140(46.7 \%)$ while only $8(2.7 \%)$ had no formal education (see Table 2$)$. Majority of the women who participated in this study had no child $124(41.3 \%)$, while $15(5.3 \%)$ had above 4 number of children (see Table 3). Majority of them were married 166 (55.3\%), 10 (3.3\%) were divorced and 114 (38\%) were single (see Table 4).

\subsection{Utilization of Contraceptives}

The study explored the use of contraceptive in the study area among the reproductive age women. The analysis of the findings by age has shown $210(70 \%)$ of the respondents have ever used contraception. Majority (70\%) of those who were using contraceptives were of age group $18-35$, while least were from above 35 years old (see Table 2). Assessing utilization of contraceptive by marital status the findings showed that single respondents 
Table 1. Socio-demographic characteristic of the respondents.

\begin{tabular}{|c|c|c|}
\hline \multicolumn{3}{|c|}{ Age distribution of the respondents } \\
\hline Age group (years) & Frequency $\mathrm{n}=300$ & Percent \\
\hline$<18$ & 13 & $4.3 \%$ \\
\hline $18-35$ & 216 & $72 \%$ \\
\hline$>35$ & 71 & $23.7 \%$ \\
\hline \multicolumn{3}{|c|}{ Distribution of the respondents by level of education } \\
\hline Level of education & Frequency & Percent \\
\hline No formal education & 8 & $2.7 \%$ \\
\hline Primary & 140 & $46.7 \%$ \\
\hline Secondary & 152 & $50.6 \%$ \\
\hline \multicolumn{3}{|c|}{ Distribution of the respondents by parity } \\
\hline Parity & Frequency $n=300$ & Percent \\
\hline No child & 124 & $41.3 \%$ \\
\hline $1-2$ & 85 & $28.3 \%$ \\
\hline $3-4$ & 74 & $24.7 \%$ \\
\hline$>4$ & 17 & $5.7 \%$ \\
\hline \multicolumn{3}{|c|}{ Distribution of the respondents by marital status } \\
\hline Marital status & Frequency $\mathrm{n}=300$ & Percent \\
\hline Single & 113 & $37.7 \%$ \\
\hline Married & 166 & $55.3 \%$ \\
\hline Cohabiting & 11 & $3.7 \%$ \\
\hline Divorced & 10 & $3.3 \%$ \\
\hline
\end{tabular}

Table 2. Socio-demographic characteristics of the respondents who ever used contraceptive.

\begin{tabular}{|cc|}
\hline & Utilization of contraceptive by marital status in $\%$ \\
\hline Marital status & Respondents using contraceptive by marital status in $\% \mathrm{n}=210$ \\
\hline Single & 69.1 \\
Married & 22.4 \\
Divorced & 3.3 \\
Cohabiting & 5.2 \\
Total & $\mathbf{1 0 0}$ \\
\hline Utilization of contraceptive by level of education \\
\hline Level of education & Using contraceptives in \% $\mathrm{n}=210$ \\
\hline No formal education & 1.9 \\
Primary & 49.5 \\
Secondary & 48.6 \\
Total & $\mathbf{1 0 0}$ \\
\hline
\end{tabular}




\section{Continued}

\begin{tabular}{cc}
\hline & Utilization of contraceptives of respondents parity \\
\hline Parity & Utilization of contraceptives of respondents parity in $\% \mathrm{n}=210$ \\
\hline No children & 23.8 \\
$1-2$ children & 36.6 \\
$3-4$ children & 32.9 \\
$>4$ children & 6.7 \\
Total & $\mathbf{1 0 0}$ \\
\hline
\end{tabular}

Table 3. Distribution of type of contraceptive method used.

\begin{tabular}{ccc}
\hline Type & Frequency $\mathrm{n}=214$ & Percentage $\%$ \\
\hline Injectables & 66 & 30.8 \\
Pills & 55 & 25.7 \\
Condom & 38 & 17.8 \\
Rhythm & 40 & 18.7 \\
Implant & 9 & 4.2 \\
"Others & 6 & 2.8
\end{tabular}

*Others are Coitus interrupts, intrauterine devices and traditional methods.

Table 4. Reasons for not using contraceptive methods.

\begin{tabular}{|c|c|c|}
\hline Reason & Freq $\mathrm{n}=82$ & Percent $\%$ \\
\hline Against religious belief & 5 & 6.2 \\
\hline No reason & 36 & 43.9 \\
\hline Not counseled enough & 3 & 3.6 \\
\hline${ }^{*}$ Others & 2 & 2.4 \\
\hline Side effects & 18 & 21.9 \\
\hline Spouse is against & 6 & 7.4 \\
\hline Want children & 12 & 14.6 \\
\hline Total & 82 & 100 \\
\hline
\end{tabular}

* Others include husband is away on study, lactating.

ranked high on utilization of contraceptive (69.1\%) followed by married $22.4 \%$ (see Table 2 ). Even though the number of respondents from cohobating and divorced was very small, the findings showed that there was a good response towards utilization of contraceptives among these groups as well. The study examined the influence of education on utilization of contraceptive. The findings have showed education has significant influence on utilization of contraceptive when compared with those who had no formal education. However there was no remarkable difference between those who had primary (49.9\%) and those who had higher education levels (48.6\%). Evaluating utilization of contraceptives by parity, the findings showed that women with 3 - 4 children were using contraceptive more than others (32.9\% and 36.6\%) when compared to others (see Table 2).

\subsection{Commonly Preferred Method of Contraception}

Researchers were interested to know the type of contraceptive current preferred by reproductive child bearing 
respondents. Multiple responses were allowed. The analysis of the findings showed that the most commonly method used for contraception was injectables $(30.8 \%)$, followed by pills $(25.7 \%)$ coitus interrupts intrauterine devices and traditional methods were the least method preferred (2.8\%).

\subsection{Side Effects Experiences by Users of Contraceptives}

Besides the above, the study explored the side experienced by the users of contraceptive. A multiple response was allowed because there is possibility of having multiple side effects to some individuals (Birth control 2014). The questionnaire did not filter from which type of contraceptive had what type of side effects. A total of 64 (30.5\%) respondents ever used contraceptive experienced side effects in this study. A long list of side effects of contraceptives was produced. This long list of side effects were summarized and then grouped into for major groups as shown in Table 3. The findings showed the most notorious side effects were disruption in menstrual cycle, nausea, loss of weight (46.6\%) and causes cardiovascular and cancer diseases; and also headache, loin pain infertility and abdominal discomfort (44.4\%).

\subsection{Barriers on Utilization of Contraceptives}

The findings elsewhere in this study have shown $70 \%$ had ever used contraceptive. The researchers wanted to know the reasons of the $30 \%$ who were not using contraceptives. Multiple responses were allowed to capture what were claimed as side effects. The analyzed findings revealed eight factors that acted as barrier on utilization of contraceptives. However, many of the respondents $(43.9 \%)$ had no reason for not using contraceptives followed by (21.9\%) who reported fear of side effects.

Nonetheless UNFPA/India (27) argues that health risks associated with contraception are low relative to the risks of a typical pregnancy and especially to the risks of an unintended pregnancy (because a number of such pregnancies are terminated by an unsafe induced abortion).

\section{Discussion}

These study findings have been presented and analysed. The findings have shown $70 \%$ reproductive women have ever used contraceptives. Contraceptives users were higher to women aged 18 - 35 years $(70 \%)$ than to women over 35 year's age. The present findings on use of contraceptives underscore Tanzania Demographic Health Survey (TDHs) [1] (even though lower than the present findings) that has shown urban women were likely to use contraceptives (46\%) when compared to rural areas (31\%). High percentage on use of contraceptives in urban settings is also noted in other developing countries in the world [31]-[33]. Urban lifestyle, knowledge on contraceptives, access to information such as radio and TV on the importance on the use of contraceptives, availability of competent service providers of contraceptives help to explain the high use of contraceptives in Dar-es-Salaam city and other urban areas in developing countries. Overall, the present findings are higher than the national average of users of contraceptives (34\%) and also for the countries south of the Sahara (22\%) of the productive age women who are users of contraceptives [1] [32], but lower than the national average of South Africa (61.2\%), Asia (66\%) and Latin America (73\%) [32].

Assessing the use of contraceptives by marital status, the findings in this study show that single women ranked first (69.1\%) when compared to married women. Swarts [33] and Cleland [4] have showed similar findings that unmarried women were leading on utilization of contraceptives. The possible underlying reasons for high use of contraceptives among unmarried women include; level of education, freedom of choosing what she wants on reproductive health, prevent unwanted pregnancy and HIV and STIs and spacing the children. Married women on the other hand in this study the findings have shown $22.4 \%$ have ever used contraceptives. Low use of contraceptives among married women is also reported by TDHs [1] and other developing countries [4] [34]-[36]. The possible explanation for low use of contraceptives among married women include: no freedom of using contraceptives because it has to be discussed by her husband and other key people in the family based on the value of the children (male or female) in the family and the community [20]. Some husbands and key family members are be supportive on use contraceptives [20] [28] because it is prestigious to have many children that will act as labour force in the family before getting married in subsistence communities. In such cases, culture of the community influences number of children to be born; and women had no choice on the number of the children to produce in her lifetime. As shown by Williamson et al. [35] in their study partners manipulated, forced, threatened, and used violence to young women not to use contraception. But this is likely to change with time 
when married couples will be leaving far away from parents; and the improved health services and standard of leaving in communities.

Educational level is regarded as a proxy determinant on use of contraceptives, but in this study educational level did not show any significant impact on use of contraceptives when compared to other studies within the country [1] and outside the country reviewed [4] [33] [34]. The possible explanation is the sample size in the present study; and the study was carried in urban area where most of the people have access to information and services on contraceptives regardless on level of education.

Whereas on the type of contraceptives being used for family planning, the present findings have shown a little shift from oral pills and traditional methods that were frequently being used [1] to injectables (30.8\%) compared to $25.7 \%$ who were users of pills. The present study findings also underscore TDHs [1] findings that show injectables are leading methods and being used by $11 \%$ of married women. TDHs [1] has furthers argued the proportion using injectables in Tanzania has gradually increasing from less than 1 percent in 1991-92, then 6\% c in 1999 and 11 percent in 2010 [1]. The shift from pills and traditional methods is also reported in African countries south of the Sahara (35) and other developing countries [21] [31] [34]. The key question is what has led to this shift from pills to injectables worldwide? Is it because the claimed side effect of pill being associated development of cancer [28] [37] [38] to women who are/have using/used contraceptive or its effectiveness? But studies on injectables show to have serious side effects to women; two third of any population using injectable contraceptive experience irregular menstrual periods, have effect on calcium stored in bones that leads to loss of bone mass and have higher risk for osteoporosis. Above all even it protects endometrial cancer, increases the risk some other cancers [39] [40].

The analyses of the findings have shown $30.5 \%$ of women who ever used contraceptives experienced side effects (see Table 5). The most reported common side effects included disruption of menstrual cycle, headache, vomiting, cancer and cardiovascular diseases. Whereas the study in Great Britain revealed weight gain, cardiovascular and cancer risks among users of contraceptives were associated with complications of contraceptives [37]. Besides that also side effects of contraceptives have been reported among the literature reviewed [41]. For example, Williamson et al [35] have argued that the major concerns is over experienced and perceived side effects of hormonal contraceptive methods, particularly menstrual disruption and risks associated with cancer. Similar findings have been echoed by other studies worldwide [42]-[45]. In addition UNFPA and Ministry of health and family welfare government [28] has also shown the following side effects nausea, vomiting, breakthrough bleeding decreased, breast changes (oedema, heaviness and tenderness) vaginal discharge and weight gain. The present findings and those found from literature show that modern contraceptive several side effects. Promoters of contraceptives argue that these are minor side effects when compared to the results of not using contraceptives [28]. If one happens to visit the cancer hospital/clinics might cry to see how women are affected with cervical and breast cancer leave alone other side effects like dizziness, nervousness, change in skin colour, breast tenderness and loss of hair [38] [39]. It is very likely that some women have been left by their husbands for prolonged bleeding. Like in other drugs there is a need to look for alternative from herbs that have shown to have effect on preventing conception [18] [19] and also promoting the natural methods [19] as well as condoms that have a dual role of HIV and STIs.

\section{Conclusion}

The findings of this study have been analyzed and discussed. The overall findings show that $70 \%$ of respondents have ever used contraceptive, which is higher than national average of reproductive women living in urban centers. The possible explanations for increased use of contraceptive are urban lifestyle, accessibility to information

Table 5. Side effects of the contraceptives used.

\begin{tabular}{ccc}
\hline Side effect & Frequency n $=\mathbf{6 4}$ & Percent \% \\
\hline $\begin{array}{c}\text { Disruption in menstrual cycle, nausea, loss of weight } \\
\text { Causes Cardiovascular and cancer diseases; }\end{array}$ & 27 & $42.2 \%$ \\
and also headache, loin pain infertility and abdominal discomfort & 30 & $46.9 \%$ \\
Weight gain and obesity & 4 & $6.2 \%$ \\
Decrease libido and not reliable & 3 & $4.7 \%$ \\
\hline
\end{tabular}


and products of contraceptives in the study area. Further important aspects noted in this study and also reflected in other studies within and outside Tanzania included 1) few respondents used traditional contraceptive methods as opposed in the past where traditional contraceptives were most preferred than modern contraceptives; 2 ) injectable contraceptives had replaced the pills among the modern contraceptives preferred by reproductive age women. The shift from using the pills to injectables contraceptives among the reproductive age women is also reflected worldwide. The present findings and those from reviewed literature seem to suggest that modern contraceptives are increasing being accepted by the reproductive age women. But it has to be noted that most of modern contraceptives are linked with extensive menstrual cycle disturbance and other disorders. The available modern contraceptives have several side effects and cultural not accepted by the African community, for instance, contraceptives that lead to prolonged menstrual breeding may lead to divorce or separation and these make some women not to use them. I am still convinced more research on FP we may come better methods of FP which are cultural accepted and free from side effects. These in turn will increase clients' choice and allow clinicians to make available a wider range of products for the unmet need of contraceptive.

\section{Recommendations}

Educate both men and women in the community on the importance of using contraceptive to prevent unwanted pregnancy and for child spacing.

> Providers of family planning products should educate clients contraindications, side effects, advantages and disadvantages of different contraceptives used in family planning methods so that clients choose the preferred methods.

$>$ Less invasive methods like condoms, calendar rhythm withdrawal (coitus interruptus) should be promoted as means of family planning, since they are cheap, easier to use and have fewer side effects.

\section{References}

[1] Tanzania Demographic and Health Survey (TDHS) (2010) National Bureau of Statistics and Planning.

[2] UFPA (2005) Family Planning and Poverty Reduction Benefits for Families and Nations. http://www.unfpa.org/rh/planning/mediakit/docs/new_docs/sheet4-english.pdf

[3] Creanga, A.A., Gillespie, D., Karklins, S. and Tsui, A.O. (2011) Low Use of Contraception among Poor Women in Africa: An Equity Issue. Bulletin of the World Health Organization, 89, 258-266. http://dx.doi.org/10.2471/BLT.10.083329

[4] Cleland John, G., Ndugwa, R.P. and Zulu, E.M. (2011) Family Planning in Sub-Saharan Africa: Progress or Stagnation? Bulletin of the World Health Organization, 89, 137-143. http://dx.doi.org/10.2471/BLT.10.077925

[5] Vanzo, D.J. and Admson, D.M. (1998) Family Planning in Developing Countries. An Unfinished Success Story. http://www.rand.org/pubs/issue papers/IP176/index2.html

[6] Mosby (2012) Mosby’s Medical Dictionary. 9th Edition eBook 9780323112581.

[7] WHO, USAID and Johns Hopkins (2012) Family Planning: Global Handbook for Providers. World Health Organization, USAID and Johns Hopkins University. http://www.unfpa.org/public/publications/pid/397

[8] Caroline, C. (2014) The History of Contraception. http://carolinecollard.hubpages.com/hub/The-History-of-Contraception

[9] Lesthaeghe, R., Ohadike, P.O., Kocher, J. and Page, H.J. (1981) Child Spacing and Fertility in Sub Saharan Africa: An Overview of Issues. In: Page, H.J., Ed., Child Spacing in Tropical Africa: Traditions and Change, Academy Press, London, 3-22.

[10] Gray, R.H. (1981) Birth Interval, Postpartum Sexual Abstinence and Child Health. In: Page, H.J., Ed., Child Spacing in Tropical Africa: Traditions and Change, Academy Press, London, 3-22.

[11] Arkutu, A. (1995) Family Planning and Child Spacing. In: Arkutu, AA., Ed., Health Women, Health Mothers: An Information Guide, Chap. 17, 2nd Edition, Family Care International, New York.

[12] Swantz, M.L. (1966) Religious and Magical Rites of Bantu Women in Tanzania. Academic Thesis, Helsinki. http://www.iberlibro.com/Religious-Magical-Rites-Bantu-Women-Tanzania/883108300/bd

[13] Liamputtong, P. (2007) Childrearing and Infant Care Issues: A Cross Cultural Perspective. In: Liamputtong, P., Ed., Childrearing and Infant Care Issues: A Cross Cultural Perspective, Nova Science Publishers, New York, 3-29.

[14] Moni, N. (1985) Some Cultural Factors Affecting Costs of Fertility Regulation. Population Bulletin of the United Nations, No. $17,17-38$ 
[15] Ezeh, P.J. (2007) Kinship and Childrearing in Two African Societies: A Comparative Investigation of the Orring and the Igbo of Southeastern Nigeria. In: Liamputtong, P., Ed., Childrearing and Infant Care Issues: A Cross Cultural Perspective, Nova Science Publishers, New York, 31-46.

[16] Kayombo, E.J., Afwork, W. and Prinz, A. (1997) Missing Component in Family. Planning in Tanzania. In: Ethnotherapien Therapeutische Konzept im Kurtvergleich. Curare Sondernband, 14/1997, 61-67.

[17] Kayombo, E.J. (1997) Traditional Birth Attendants (TBAs) and Maternal Health Care in Tanzania. In: Kalipen, E. and Thiuri, P., Eds., Issues and Perspectives on Health Care in Contemporary Sub-Saharan Africa by Studies in Africa Health and Medicine, Vol. 8, The Edwin Mellen Press, Lewston, Queenston, Lampeter, 288-305.

[18] Zeus, S. Herbal Contraception. http://www.sisterzeus.com/HContra.htm

[19] Sarah (2012) Natural Birth Control Using Herbs. http://www.thehealthyhomeeconomist.com/natural-birth-control-using-herbs/

[20] Bongaart, J. (2011) Can Family Planning Programs Reduce High Desired Family Size in Sub-Saharan Africa? International Perspective on Sexual and Reproductive Health, 37, 209-216. http://dx.doi.org/10.1363/3720911

[21] State of World Population. http://www.worldpopulationstatistics.com/world-population-2014/

[22] Ahlburg, D.A., Kelley, A.C. and Mason, K.O. (1996) The Impact of Population Growth on Well-Being in Developing Countries. Springer, New York. http://dx.doi.org/10.1007/978-3-662-03239-8

[23] Trang, P.N. (2011) Effect of Population Growth in Asian Developing Countries. Bachelor Thesis in Economics, Malardelen University, Vestaras.

[24] The Ministry of Health and Social Welfare. The National Family Planning Costed Implementation Program, 20102015. Updated 2013.

[25] Mungure, E. and Owaga, P. (2014) Family Planning in Tanzania: A Review of National and District Policies and Budgets. DSW, Deutsche Stiftung Weltbevoelkerung, Dar-es-Salaam.

[26] UNFPA (2010) Donor Support for Contraceptives and Condoms for STI/HIV Prevention. http://www.unfpa.org/public/home/publications/pid/6479

[27] UNFPA (2005) Family Planning and Povert Reduction Benefits for Families and Nations. http://www.unfpa.org/rh/planning/mediakit/docs/new docs/sheet4-english.pdf

[28] UNFPA and Ministry of Health and Family Welfare Government of India (2005) Contraceptive Updates. Reference Manual for Doctors. http://countryoffice.unfpa.org/india/?publications=362

[29] National Population Census (2012) National Bureau of Statistics and Planning.

[30] Yamane, T. (1967) Statistics. An Introductory Analysis. 2nd Edition, Harper and Row, New York.

[31] Sawsan, M.A. (2012) Barriers to Contraceptives, Geneva Foundation for Medical Educational and Research (GFMER). http://www.slideshare.net/sawsanmust/barriers-to-contraceptive-use

[32] Seiber, E.E., Bertrand, J.N. and Sullivan, T.M. (2007) Changes in Contraceptive Method Mix in Developing Countries. International Family Planning Perspectives, 33, 117-123. http://dx.doi.org/10.1363/3311707

[33] Swartz, L. (2002) Fertility and the Current South African Issues of Poverty, HIV/AIDS and Youth. A Paper Presented at the Conference in Expert Group Meeting on Completing the Fertility Transition, Organized by Department of Social Development, South Africa and Human Sciences Research Council, Pretoria, 24 October 2002.

[34] UNFPA (2014) Reducing Risk by Offering Contraceptives. http://www.unfpa.org/public/home/mothers/pid/4382

[35] Williamson, L.M., Parkes, A., Wight, D., Petticrew, M. and Hart, G.J. (2009) Limits to Modern Contraceptive Use among Young Women in Developing Countries: A Systematic Review of Qualitative Research. Reproductive Health, 6 , 3. http://www.reproductive-health-journal.com/content/6/1/3 http://dx.doi.org/10.1186/1742-4755-6-3

[36] Gilliam, M.L., Warden, M., Goldstein, C. and Tapia, B. (2004) Concerns about Contraceptive Side Effects among Young Latinas: A Focus-Group Approach. Contraception, 70, 299-305. http://dx.doi.org/10.1016/j.contraception.2004.04.013

[37] Oddens, B.J., Visser, A.P., Vemer, H.M., Everaerd, W.T. and Lehert, P. (1994) Contraceptive Use and Attitudes in Great Britain. Contraception, 49, 73-86. http://dx.doi.org/10.1016/0010-7824(94)90110-4

[38] Tolley, E., Loza, S., Kafafi, L. and Cummings, S. (2005) The Impact of Menstrual Side Effects on Contraceptive Discontinuation: Findings from a Longitudinal Study in Cairo, Egypt. International Family Planning Perspectives, 31, 1523. http://dx.doi.org/10.1363/3101505

[39] Yourcontraception.com Side Effects of Injectable Contraception. http://www.yourcontraception.com/birth-control-methods/injectables/side-effects-of-injectable-contraception.html

[40] Medical Keywords Side Effects of Injectable Contraceptives. 
http://medicalkeywords.com/contraception/side effects of.asp

[41] Kahlenborn, C., Modugno, F., Potter, D.M. and Severs, W.B. (2006) Oral Contraceptive Use as a Risk Factor for Premenopausal Breast Cancer: A Meta-Analysis. Mayo Clinic Proceedings, 81, 1290-1302. http://dx.doi.org/10.4065/81.10.1290

[42] Veljković, M. and Veljković, S. (2010) The Risk of Breast Cervical, Endometrial and Ovarian Cancer in Oral Contraceptive Users. Medicinski Pregled, 63, 657-661. http://dx.doi.org/10.2298/mpns1010657v

[43] Casey, P.M., Cerhan, J.R. and Pruthi, S. (2008) Oral Contraceptive Use and Risk of Breast Cancer. Mayo Clinic Proceedings, 83, 86-91. http://dx.doi.org/10.4065/83.1.86

[44] Iodice, S., Barile, M., Rotmensz, N., Feroce, I., Bonanni, B., Radice, P., Bernard, L., Maisonneuve, P. and Gandini, S. (2010) Oral Contraceptive Use and Breast or Ovarian Cancer Risk in BRCA1/2 Carriers: A Meta-Analysis. European Journal of Cancer, 46, 2275-2284. http://dx.doi.org/10.1016/j.ejca.2010.04.018

[45] Gaffield, M.E., Culwell, K.R. and Ravi, A. (2009) Oral Contraceptives and Family History of Breast Cancer. Contraception, 80, 372-380. http://dx.doi.org/10.1016/j.contraception.2009.04.010 